\title{
Sustainable development of agricultural product processing industry in Vietnam
}

\author{
Thi Hoai Nguyen ${ }^{1,}$, and Duc Luan Nguyen ${ }^{2}$ \\ ${ }^{1}$ Graduate Academy of Social Sciences, 477 Nguyen Trai, Hanoi 10000, Vietnam \\ ${ }^{2}$ Central Propaganda Department of the Communist Party of Vietnam, 49 Phan Dinh Phung street, \\ Hanoi, 10000, Vietnam
}

\begin{abstract}
Agricultural processing industry is a sector that has a strong impact on agriculture and rural areas and provides momentum for the development of agriculture, enhances the value of agricultural products as well as contributes to creating more jobs and increases income for employees. Therefore, sustainable development of agricultural product processing industry is indispensable in the process of industrialization, modernization and restructuring of the economy. With many advantages from tropical agriculture, the agricultural product processing industry is constantly developing in all localities across the country. Agricultural product processing industries are providing many essential commodities for the society, creating jobs for a large labor force, and at the same time bringing a large source of foreign currency from exports and contributing to the revenues of the state budget. The development of the industry is always under the combined impact of domestic and international factors, in which, socio-economic factors have greatly impacted the sustainable development of the agricultural product processing industry. This paper mention to the sustainable development of agricultural product processing industry in Vietnam in recent years.
\end{abstract}

\section{Introduction}

The agricultural product processing industry is a traditional industry that has become a key industry with an important role in the economy in Vietnam. With many advantages from tropical agriculture, the agricultural product processing industry is constantly developing in all localities across the country. In the Project for restructuring the agriculture sector approved by the Prime Minister in Decision No. 899/QD-TTg dated June 10, 2013, it is clearly stated: "Prioritize the investment in the processing industry, upgrade of technology and equipment, production organization, and sale to increase added values; each product line reaches at least $20 \%$ of added value within 10 years". Up to now, Vietnam has formed and developed a system of processing and preserving agricultural products with about 7,500 industrial-scale facilities associated with exports, along with thousands of small, retail and household-level agricultural product processing establishments that spread throughout the localities to do preliminary processing and processing activities for domestic consumption.

${ }^{*}$ Corresponding author: luanvfu@gmail.com 
Agricultural product processing industries are providing many essential commodities for the society, creating jobs for a large labor force, and at the same time bringing a large source of foreign currency from exports and contributing to the revenues of the state budget. The development of the industry is always under the combined impact of domestic and international factors, in which, socio-economic factors have greatly impacted the sustainable development of the agricultural product processing industry.

\section{Materials and methods}

We uses a combination of research methods, such as: Comparing jurisprudence, statistics, analysis, synthesis, interpretation, inductive method... With the rich of references from textbooks on agricultural processing industry, sustainable development of relevant domestic and foreign authors, we analyze and compares to clarify research issues.

\section{Results}

\subsection{Socio-economic factors affecting the sustainable development of Agricultural Product Processing Industry}

The agricultural product processing industry is a group of processing industries, mainly carrying out the preservation, improvement, and raising of use-values and value of agricultural raw materials by industrial methods. According to the Prime Minister's Decision No. 10/2007/ QD-TTg of January 23, 2007 issuing "the system of economic branches of Vietnam", the food production and the processing industry is the secondary economy including subsectors such as Processing and preserving meat and meat products; Processing and preserving aquatic products and products from aquatic foods; Processing and preserving vegetables and fruits; Production of animal and vegetable oils and fats; Processing milk and milk products; Milling and producing flour; Producing other food; Producing feed for cattle, poultry, and aquatic animals. These industries are mainly small and medium-sized, raw materials of them are seasonal and their products are diverse and plentiful. However, this industry is highly dependent on nature with high risk. The influence of seasonality and operating time in the year of processing facilities are often short, so the ability to recover investment capital is difficult.

According to Section 4, Article 3 of the Law on Environmental Protection, sustainable development is defined as "development that meets the needs of the current generation without compromising the ability of future generations to meet those needs based on a close and harmonious combination between economic growth, ensuring social progress and environmental protection". Since then, it can be seen that the sustainable development of the agricultural product processing industry is the process of creating a sustainable socioeconomic and environmental system to meet the current needs of developing the agricultural product processing industry without compromising the ability to meet the needs of future development and to be accepted by society. That manifested in economic, social and environmental sustainability.

This development process has been under the aggregate impact of socio-economic factors in both positive and negative ways. In particular, economic and social factors are not separated from each other but linked together. In that unity, production relations are factors that both contribute to the composition and participate in controlling other factors. Next is the relationship in the organization that manages the social production which governs the economic management mechanism, the mode of operation of an economy, thereby awakening the potential of society. Finally, labor product distribution relations 
define the mode and size of the income of members in society and are the direct economic causes leading to fairness or injustice, equality or inequality and rich-poor division in society. Socio-economic factors stem from economic factors and relations, including the social structure of the economy, social-class structure, and social consequences of economic change such as social division, rich-poor division, social value orientation, social justice, social progress, etc.

\subsection{The positive impacts of socio-economic factors on sustainable development of agricultural product processing industry}

With the increasingly improved socio-economic infrastructure, it has created favorable conditions for upgrading facilities and creating a foundation for the development of agricultural product processing industries. In the renovation years, localities all over Vietnam have paid attention to investing in infrastructure construction, especially transportation, electricity, and water. Many industrial zones have been established along with the process of building infrastructure in the new rural construction program, gradually synchronizing infrastructure and creating auspicious conditions for the processing industry to develop towards modernization, expanding scale and improving product quality. In addition, the technical and material facilities serving and supporting agricultural production have been increasingly invested and upgraded, creating advantageous conditions for agricultural production to develop and achieve high productivity, output and quality as well as creating abundant raw materials for the agricultural product processing industry.

With that, the achievements in education and training, science and technology have directly affected the production level of processing industries. The cause of education and training in Vietnam has had positive changes. For instance, science and technology have a new development which makes the qualifications and capacity of employees be improved and creates progressive changes in the quality of human resources of agriculture and agricultural product processing industries. This is a decisive factor for technical improvement, application of scientific and technological advances, creating innovation and creativity in the production process and contributing to improving labor productivity and quality of the product in order to meet the market demand better. So far Vietnam has a number of industries with relatively modern technology and processing equipment of regional and global levels such as processing cashew nut, coffee, rice, shrimp, Pangasius catfish, etc.

At the same time, the economic structure also creates an alteration in the extent and structure of processing industries. Although the proportion of the agricultural sector has decreased, the output and quality of agricultural products have increased along with the process of forming intensive farming areas with applying large-scale production models and using scientific advances in production processes. This has created a large, stable and quality material source for processing industry production. Particularly, mechanization in agriculture has been more and more widely applied (the rate of mechanization in soil agricultural stage reaches $94 \%$; sowing and planting stage reaches $42 \%$; caring stage reaches $77 \%$; rice harvesting stage reaches $65 \%$ ). Up to now, the domestic mechanical industry has produced engines and tractors with a capacity of up to 30 horsepower, accounting for more than $30 \%$ of the domestic market share; combine harvesters account for $15 \%$. Vietnam has 7,803 mechanical enterprises and nearly 100 establishments manufacturing agricultural machines and equipment. Along with that, the industries supporting the development of the processing industry are also gradually changing, creating favorable conditions to enhance the production process and improve the products' quality of the processing industry. The establishment and development of industrial parks in association with international-standard agricultural production zones create a close link 
between agricultural cooperatives and agricultural product processing companies, bringing high production efficiency.

Production of the processing industry has many opportunities to develop under the impact of a market economy with many ownership regimes and many economic sectors. A lot of business enterprises were born, innovated and developed. Many forms of association, cooperation and joint venture between domestic and foreign enterprises have brought practical results. In particular, agricultural product processing industries have chances to access capital easier to facilitate investment in production. Commercial banks have actively implemented many credit packages to support the development of rural industries, supporting industries and production in craft villages. Enterprises have the occasion to acquire modern science and technology, advanced techniques from developed countries as well as taking advantage of foreign investment capital and other important resources. Many businesses have actively invested in and built factories, facilities specializing in purchasing, preliminary processing and processing of agricultural products. A number of foreigninvested enterprises are allowed to invest to develop, increase production capacity and quality of processed products, and improve competitiveness in the market. Traditional businesses have actively exploited the source of raw materials as well as consumer markets. Private enterprises and foreign-invested enterprises have always shown their acumen in capturing consumers' needs and tastes, actively investing in production lines of modern processing machinery and equipment with high technology to create many kinds of refined and deep processed products which have large production values and high economic efficiency. Currently, many big enterprises and corporations have been interested in and implemented investment projects in the field of processing agricultural products with advanced processing technology on vegetables and fruits, shrimp, Pangasius catfish, slaughtering cattle and poultry, coffee, wooden furniture, etc.

In particular, the expansion of domestic and foreign markets has created advantageous conditions for agricultural product processing enterprises to expand their scale, improve the quality and efficiency of production. The size and growth rate of market demand allows the agricultural product processing industry to exploit large-scale advantages while encouraging businesses to invest in equipment, improve technology and labor productivity. Now Vietnam's agricultural consumption market is expanded with more than 185 countries and territories, becoming a major exporter of agricultural products in the world with 10 key products with export turnover of over USD 1 billion. such as rice, coffee, rubber, cashew, pepper, tea, vegetables and fruit, Pangasius catfish, shrimp and timber. In addition, Vietnam has signed a free trade agreement (EVFTA) and investment protection agreement (EVIPA) with the European Union, therefore, an opportunity to expand the market for Vietnam's exports of agricultural, forestry and fishery products are very big.

In the period from 2013 to 2019 , the country's agricultural product processing industry has grown strongly on both modern scale and level compared to 5 years ago (2007 - 2012). The annual growth rate of added value is about 5 to $7 \%$, exports account for about $65 \%$ of the total processing value. Vietnam continues to maintain eight commodity groups with an annual export turnover of USD 1 billion or more, of which four items have a turnover of over USD 3 billion.

Social life has been increasingly improved. This has created terms for raising incomes and living standards of workers, farmers and other classes in rural areas. This is also a very important condition for social stability and development in localities, especially the area of agricultural product processing industry development. In fact, when the material and spiritual life of workers and farmers has been raised, many households have risen to get rich in their own homeland and get rich from agriculture. Processing industries have changed their perceptions in the process of participating in the agricultural production, trading and processing chains. These will make a big and positive impact on customs, 
production and consumption needs.

Simultaneously, the association in production makes the basis for social cohesion. The formation and diversification of forms of cooperation, linkages, and economic exchanges have created effective and sustainable models of production and business. Typical of this connection are some models such as Lam Son Sugar Joint Stock Company, Duy Son 2 Advanced Cooperative, the 50 million ha field model at first in Thai Binh then spreading to the whole country, the model of engineers hiring contract of farmers in Hoa An commune, $\mathrm{Cau} \mathrm{Ke}$ district, Tra Vinh province,... This cooperation link has shown the unity of economic benefits of the State, farmers, businesses, and scientists. It creates a strong development for the production process, connects the company with the raw material areas and links stable and sustainable cooperation with agricultural, rural production and farmers with the strong support of scientists. Thanks to the essential and effective methods of association, the companies have created thousands of jobs; workers and farmers are increasingly earning high income and this contributes to poverty reduction in rural areas. The linkage and cooperation create unity between workers, farmers, intellectuals, and businessmen to realize their economic benefits together and to create a sustainable social basis for the development of agricultural production as well as the agricultural product processing industry. On that basis, social relations are increasingly expanded, diversified and the relationship between different social classes in society develops in various forms, methods, and levels. The social network is more and more open broadly, therefore, members in society not only have relationships in the family and community but also have relationships on a national and international extent, not only creating social cohesion but also creating conditions for expanding production.

Thanks to increasingly synchronized infrastructure, the observance of enterprises, production households and agricultural cooperatives to the law on environmental protection has been raised. This contributes to improving and protecting the environment of the agricultural product processing industry market. In most localities, the wastewater treatment capacity of centralized wastewater treatment plants in industrial parks has met the total wastewater source of enterprises; the quality of wastewater treatment plants has been increasingly improved; waste treatment in industrial parks and export processing zones has gradually entered into a routine and made positive changes. In the treatment of exhaust fumes, due to the attention, evaluation, and consideration right from the establishment phase of the project, many enterprises in industrial parks and export processing zones have invested in building exhaust gas treatment systems. Some industries with high levels of exhaust emissions such as manufacturing of construction materials, mechanics, etc have also actively taken preventive measures. Therefore, the pollution of exhaust fumes and noise in industrial parks is somewhat limited. In parallel with the above activities, the implementation of regulations on solid waste treatment is strictly followed by most enterprises. The majority of enterprises in industrial parks and export processing zones have taken measures to classify and temporarily store them before collecting them to the treatment sites. Some industrial parks and export processing zones have organized centralized collection and treatment of waste. Thus, basically, the collection and treatment of solid waste are guaranteed. The air quality in rural areas is still quite good. Many areas such as the mountainous and purely agricultural region and have no signs of pollution.

\subsection{The negative impacts of socio-economic factors on sustainable development of agricultural product processing industry}

Besides the positive impacts, the existence of socio-economic factors also negatively affect the development of the agricultural product processing industry.

Infrastructure in some localities is not synchronized and still faces many difficulties, 
especially in mountainous and ethnic minority areas. The quality of human resources is still low and mainly untrained manual labor. The majority of rural workers and female workers are passive. Their working time is free but they are afraid of acquiring new things and accessing science and technology, skills and knowledge to meet the needs of the agricultural product processing industry. Many foreign-invested processing enterprises (with advanced technologies) want to invest in construction, but due to the lack of highquality human resources, foreign investors have not been eager to invest and if so, they only invest at a certain level with a moderate scale.

At once, the agricultural product processing industry is associated with raw material areas in the countryside and farmers, so it is also negatively affected by the ideology of smallholders and small producers. The adjustment of the scale of agricultural production, the formation of "Large fields", farms, ranch, barracks and the level of mechanization in agricultural production is still low and not comprehensive. The level of equipment is outdated, most tiller machines are small and only suitable for household size and fragmented soils. Even the transfer or mobilizing people to change the form of cultivation and production is also very difficult because of small, fragmented production and "small farmers" style has been ingrained in the farmers' habit of thinking and way of doing. In addition, the investment capital for the agricultural product processing industry is still low and the capital recovery capacity is slow.

These limitations are a great obstacle to the expansion of production scale, to the improvement of technological levels and to the enhancement of quality and production efficiency of agricultural product processing enterprises. In fact, the current level of processing technology in Vietnam is at the average level of the world with old equipment, outdated technology and low productivity. Equipment innovation coefficient is only $7 \%$ per year (equal to $1 / 2$ to $1 / 3$ of the minimum of other countries). The main processed products are still semi-processed products with low added value (accounting for 70 to $85 \%$ ). The number of small and medium-sized agricultural, forestry and aquatic product processing establishments and households accounts for about $95 \%$. The processing capacity of some sectors is still weak and there is a lack of facilities and processing capacity, especially at peak seasons. For vegetables and meat products, the amount currently put into processing accounts for only 5 to $10 \%$ of the annual output. Other items such as sugar cane, rice, coffee, vegetables and fruits, seafood,... also do not have enough processing capacity when entering the main season. This often causes a backlog situation that reduces the quality of agricultural products and loses their prices. These things have made the quality of our agricultural products unstable and there is a potential risk of unsanitary and unsafe foods, reducing competitiveness in the domestic and international markets. In particular, with the outdated processing line, many businesses have not been able to adapt to new changes in the integration period, so they are confusing, especially to ensure the technical standards to obtain processed agricultural products that meet the rigorous standards of fastidious markets. Therefore, products of the agricultural food processing industry face fierce competition from countries with developed economies and the agricultural product processing industry with modern technology.

Differences in qualifications and living conditions lead to differences in access to opportunities, employment and development resources. Along with that, the impact of the negative side of the market economy creates income inequality, the disparity in living standards, leading to social division, rich-poor division tends to increase. A part of farmers is richer and became small owners; another part is poorer and became a hired employee or joined an industrial workers team. This directly affects the lives of workers and farmers, thereby negatively affecting social relations in rural areas. In particular, the market economy has led to the emergence of extreme, egocentric individualism, disregard of collective interests and social interests. It makes social links become loose; humanity and 
justice can be despised, abused, and undermined social cohesion. Many traditional institutions in rural areas have been broken down. Family relations, lineages and villages have shown many signs of lack of cohesion and close attachment. The phenomenon of expatriate and leaving agriculture is relatively common, in addition to the pressure of life has reduced the attachment of community members.

Besides, the land disputes, economic business competition and conflicts of interest make social relations have many negative changes. In some countryside areas, farmers give their land to enterprises, but when the enterprise comes into operation, only a small part is arranged for jobs, the rest become unemployed. From having productive land, having a job, earning income, farmers become unemployed. This makes farmers in many places be frustrated and not interested in enterprises, they even cause difficulties and hinder the production of the factory that causing damage to businesses and workers. Many agricultural product processing factories are built in rural areas to purchase agricultural products to process for export, therefore, many businesses have signed contracts with farmers to supply raw materials for the factory. Because of the immediate benefits, a part of farmers broke the economic contract with the business and sold agricultural products to private traders at a higher price. This makes business enterprises have no production materials and have to close or operate in a standstill, businesses suffer losses; workers do not have enough jobs and wages are cut; scientific-technical staffs do not have a salary and life faces many difficulties. Meanwhile, there are a number of businesses that buy agricultural products and give different reasons to squeeze prices for agricultural products. This causes farmers to lose out and do not have an interest. There are businesses that only care about profits but do not pay attention to reinvestment for farmers, do not create a sustainable, long-term relationship between businesses and farmers. Along with that, at present, there is a price difference between industrial goods and scientific products with prices of agricultural products, which gives farmers many disadvantages in agricultural production. Farmers have to buy materials for production at high prices while the prices of agricultural products are low, in the long run, that will affect the revenue of businesses and the income of workers and farmers.

Currently, the infrastructure in some localities is not synchronized. There are still many difficulties. Outdated production technology has directly affected the treatment of industrial waste and caused environmental pollution. Accompanying with development are the risks of environmental pollution from the waste of living and production activities as well as the impact of industrial parks and clusters. Waste from these activities is polluting the air, water and soil, and there is an increasing trend, especially in rural solid waste which has raised alarm bells in many regions and localities. In addition, the farmers' and workers' awareness and responsibility for environmental protection are limited, especially the use of pesticides by farmers in some localities is not in compliance with the standards and has harmed the soil and water environment. This has led to local air pollution in some craft villages and areas where industrial clusters are located alternatively in residential areas, or in some regions where rural infrastructure upgrading is taking place.

In particular, agricultural production and processing facilities which are small scale, scattered, spontaneous development and using outdated technology equipment, are causing pollution and putting pressure on the rural environment. More dangerously, every year, agriculture food processing plants discharge into the environment a large amount of waste in all three forms: gas, liquid, and solid through the production process which consumes energy and water as well as releases discarded substances during processing or packaging. The waste characteristics of agricultural food processing facilities are organic and stinking. They directly affect not only the ecological environment and agricultural production activities but also the daily life of people in rural areas. The above-mentioned wastes have not been collected and treated, so they polluted the soil and water environment, especially 
spreading the stench into the surrounding environment.

\section{Conclusion}

Along with the development process of Vietnam, socio-economic factors have undergone strong changes and comprehensively affect in different directions to the process of economic development in general and sustainable development of the processing industry in particular. On the one hand, socio-economic factors create very favorable conditions, prerequisites, and incentives for the processing industry to expand its scale, to improve its qualifications, quality, and production efficiency, to enhance the lives of workers, to build and strengthen good relationships in society as well as preserving and protecting the living environment. On the other hand, the negative changes and the existence of these factors also hinder the sustainable development of the agricultural product processing industry. Facing the impacts of socio-economic factors, the agricultural product processing industries need to take advantage of and promote the positive, prevent and limit negative impacts in order to create new occasions and opportunities to continue to rise up. Only so, they can affirm its position and role in the national economy as well as contributing to the country's sustainable development in new conditions./.

\section{References}

1. Ngo Dinh Giao, Food processing industry in Vietnam (National Political Publishing House, Hanoi, 1998)

2. Nguyen Thi Minh Hien, Asia - Pacific Economic Review 367, (2012)

3. The National Assembly of the Socialist Republic of Vietnam (2015), The Law on Environmental Protection in 2015, Hanoi

4. A. Dang, S. Goldstein, J. McNally, The International Migration Review, 31(2), 312337 (1997) doi:10.2307/2547222

5. P. Taylor, Journal of Vietnamese Studies 2(2), 3-56 (2007) doi:10.1525/vs.2007.2.2.3

6. Q. Dinh, ASEAN Economic Bulletin 16(3), 373-393 (1999) Retrieved April 13, 2021, from http://www.jstor.org/stable/25773599

7. J. Benedict T. Kerkvliet, The Journal of Asian Studies 54(2), 396-418 (1995) doi:10.2307/2058744

8. T. Que, ASEAN Economic Bulletin 15(1), 30-46 (1998) Retrieved April 13, 2021, from http://www.jstor.org/stable/25773511 